\title{
CRISE E TRANSMODERNIDADE: FUNDAMENTOS INICIAIS PARA UMA ÉTICA DA LIBERTAÇÃO
}

\author{
Bruno Meneses Lorenzetto* \\ Pedro Ribeiro Giamberardino**
}

\section{RESUMO}

O presente estudo visa contextualizar a crise do paradigma da modernidade na sociedade contemporânea, sob uma perspectiva crítica. Para tanto, delineia-se os aspectos fundadores da racionalidade moderna, pautados em seus padrões de pureza, de forma articulada ao seu respectivo fenômeno de desencantamento. A seguir, pautase a análise referente à crítica à modernidade sob a perspectiva traçada pela Escola de Frankfurt e pela proposta da transmodernidade, delineada especialmente a partir da Filosofia da Libertação, como possibilidade de uma fundamentação para o princípio da dignidade humana, de modo conciliável à alteridade e à diferença. Adota-se esta corrente, portanto, como fundamento de uma ética compatível à efetividade dos Direitos Humanos e os direitos fundamentais, sem que estes conceitos venham a significar uma sobreposição da cultura ocidental sobre os demais países e culturas, respeitando as necessidades globais e as especificidades locais.

Palavras-chave: Crise da modernidade; desencantamento; alteridade; dignidade.

SUMÁRIO: 1 ESTADO DA ARTE: OS PADRÕES DE PUREZA DA MODERNIDADE; $1.1 \quad \mathrm{O}$ DESENCANTAMENTO DO MUNDO MODERNO; 1.2 AS FACES EXCLUDENTES DO PROJETO MODERNO; 2 FUNDAMENTOS DA CRÍTICA À MODERNIDADE: UM PROJETO NÃO CUMPRIDO; 2.1 CONTEMPORANEIDADE: MODERNA OU PÓSMODERNA?; 3 A PROPOSTA DA

${ }^{*}$ Mestrando em Direito das Relações Sociais pela UFPR. Bacharel em Direito pela Pontifícia Universidade Católica do Paraná. Monitor da Cadeira de Teoria do Direito e Hermenêutica Jurídica. E-mail: bruno_lorenzetto@yahoo.com.br

** Graduando em Direito pela Pontifícia Universidade Católica do Paraná. Bolsista do CNPq. E-mail: pedro_giamberardino@yahoo.com.br 
CRISE E TRANSMODERNIDADE: FUNDAMENTOS INICIAIS PARA UMA ÉTICA DA LIBERTAÇÃO

TRANSMODERNIDADE: EM BUSCA DA ALTERIDADE; 4 CONSIDERAÇÕES FINAIS; 5 REFERÊNCIAS.

\section{ESTADO DA ARTE: OS PADRÕES DE PUREZA DA MODERNIDADE}

Desde o século XVIII passou-se a reproduzir, em escalas crescentes, a expressão modernidade. Em conseqüência, o tempo moderno, como enunciado de mudança, de ruptura entre momentos históricos, ganhou força tamanha ao ponto de se incorporar à linguagem em todas as instâncias sociais. Tratada, primariamente, como marco temporal histórico, a modernidade ultrapassou (em muito) sua função inicial, tornando-se determinante de conteúdos ${ }^{1}$, meio qualitativo, e estendeu seu significado para a simbólica representação do abismo que separava aqueles que eram tidos como antigos em oposição ao novo, ao moderno.

O nascimento da modernidade, difundindo-se tanto no ideário social, como na lingüística ocidental, acarretou a formação de uma consciência de transição, ruptura com o passado, ao mesmo tempo em que desestabilizou o solo em que as pessoas fincavam seus pés ${ }^{2}$. O forte conteúdo de mudança e os valores que esta trazia não

1 "Pero el número enorme de teorías de las épocas históricas no se nutre de determinaciones temporales, sino de determinaciones de contenido, objetivas o personales proporcionándole a la época de que se trate su peculiaridad. (...) Y, finalmente, existen cada vez más intentos de clasificar las épocas según su estructura organizativa espiritual, política, social o económica, siendo estol o que caracteriza a la "modernidad"." (KOSELLECK, Reinhart. Futuro pasado. Para uma semântica de los tiempos históricos. Barcelona: Paidós, 1993, p. 291). Ainda sobre a questão expõe Habermas: “A classificação, ainda hoje usual (p. ex., para a caracterização de disciplinas de história), em Idade Moderna, Idade Média e Antiguidade (respectivamente História moderna, medieval e antiga), só pôde se compor depois que as expressões "novos tempos" ou "tempos modernos" ("mundo novo" ou "mundo moderno") perderam o seu sentido puramente cronológico, assumindo a significação oposta de uma época enfaticamente "nova"." (HABERMAS, Jürgen. O discurso filosófico da modernidade: doze lições. São Paulo: Martins Fontes, 2000, p. 9).

2 "La determinación de la modernidad como tiempo de transición no ha perdido en evidencia epcoal desde su descubrimiento. Un critério infalible de esta modernidad son sus conceptos de movimiento - como indicadores del cambio social y político y como factores lingüísticos de la formación de la conciencia, de la críticia ideológica y del control del comportamiento." (KOSELLECK, op. cit., p. 332). 
foram, portanto, recepcionados de maneira homogênea por todos os lugares do mundo e, ainda hoje, muitos se questionam acerca do projeto da modernidade e suas promessas (tidas mormente como não cumpridas).

Nesse sentido, o projeto da modernidade, segundo análise de Jürgen Habermas, não se concluiu, pois, o que se percebe nos diversos discursos filosóficos contemporâneos é a presença disseminada de vários pós: pós-analíticos, pósestruturalistas, pós-marxistas ${ }^{3}$, ou seja, a superação (ou tentativa) dos paradigmas vigentes por outros modelos que correspondam às diversas mudanças sociais vivenciadas na contemporaneidade.

Analisando-se o que representa a modernidade, verifica-se que esta se caracteriza pela tríade fundamental da universalidade, da individualidade e da autonomia $^{4}$. A universalidade se opõe ao particularismo, apresentando o projeto da modernidade a todos os seres humanos sem qualquer forma de distinção, importante conquista que corrobora o conteúdo da igualdade formal. A individualidade se opõe à invisibilidade das pessoas quando reunidas ou pensadas como massas, multidões, números que podem ser somados ou subtraídos; a individualidade valoriza ainda a vida

${ }^{3}$ De acordo com: HABERMAS, Jürgen. Pensamento pós-metafísico: estudos filosóficos. Rio de Janeiro: Tempo Brasileiro, 1990, p. 11.

${ }^{4}$ Segundo Rouanet: "O projeto civilizatório da modernidade tem como ingredientes principais os conceitos de universalidade, individualidade e autonomia. A universalidade significa que ele visa todos os seres humanos, independentemente de barreiras nacionais, étnicas ou culturais. A individualidade significa que esses seres humanos são considerados como pessoas concretas e não como integrantes de uma coletividade e que se atribui valor ético positivo à sua crescente individualização. A autonomia significa que esses seres humanos individualizados são aptos a pensarem por si mesmos, sem a tutela da religião ou da ideologia, a agirem no espaço público e adquirirem pelo seu trabalho os bens e serviços necessários à sobrevivência material." (ROUANET, Sergio Paulo. Mal-estar na modernidade: ensaios. São Paulo: Companhia das Letras, 1993, p. 9). A interpretação de Rouanet tem forte inspiração no posicionamento Iluminista. Ainda sobre a questão expõe Medeiros: "Na modernidade (a partir de meados do século XVIII), a subjetividade passa a ser tematizada na ordem da fundamentação. $O$ sujeito (razão transcendental/ consciência) se torna a condição de factibilidade do restante. As características marcantes desse paradigma são: individualidade (o indivíduo, visto de forma ético-positiva, é a referência central, o que caracterizou a ideologia liberal do laissez-faire); autonomia (há a emancipação do intelecto do indivíduo, que não mais necessita da tutela do Estado e da Igreja, o que leva a um rompimento com a tradição e a autoridade) e universalidade (pretende a inclusão de todos sob um ponto de vista idealista, isto é, o projeto de emancipação encontra o universal do humano, que se configura como base da episteme iluminista). Este projeto teve início com Descartes, passando por Kant, Hegel, entre tantos outros." (MEDEIROS, Ana Letícia B. D. Direito internacional dos direitos humanos na América latina: uma reflexão filosófica da negação da alteridade. Rio de Janeiro: Lumen Juris, 2007, p. 36-37). 
de cada pessoa em sua essencialidade original. A autonomia se opõe à alienação, é a capacidade das pessoas se pensarem como sujeitos, como detentores de direitos, é o conteúdo que mais se aproxima da emancipação humana.

\subsection{O DESENCANTAMENTO DO MUNDO MODERNO}

A modernidade demonstrou que seu conteúdo enfrentava uma grande contradição quando se formaram frentes modernas que buscavam moldar solidamente padrões de segurança e ordem, paralisando os levantes de transformação social. Sob esse prisma, o mundo ideal que correspondia às fantasias desse paradigma ${ }^{5}$, passou a se confrontar com o seu próprio conceito, por não trazer em si a dinamicidade da mudança, do rompimento com a tradição.

Percebe-se, assim, que o mundo ideal moderno tornou-se, em amplo sentido, anti-moderno, pois passou a conservar valores que a modernidade havia proposto romper. Conforme demonstra Olgária $\mathrm{Matos}^{6}$ :

No apogeu da sociedade ocidental que se considera lógica, na qual a ciência prometeu segurança e bem-estar, o atual estágio da acumulação capitalista cria a "civilização do pânico". Ela desvincula-se à passividade e à angústia existencial da perda do controle da

${ }^{5} \mathrm{O}$ termo paradigma é aplicado de acordo com o conceito elaborado por Thomas Kuhn, que diz: "Percebe-se rapidamente que na maior parte do livro o termo "paradigma" é usado em dois sentidos diferentes. De um lado indica toda a constelação de crenças, valores, técnicas, etc. .., partilhadas pelos membros de uma comunidade determinada. De outro, denota um tipo de elemento dessa constelação: as soluções concretas de quebra-cabeças que, empregadas como modelos ou exemplos, podem substituir regras explícitas como base para a solução dos restantes quebra-cabeças da ciência normal." (KUHN, Thomas S. A estrutura das revoluções científicas. 5. ed. São Paulo: Perspectiva, 1998, p. 218). A idéia de paradigma será usada, portanto, como uma construção conceitual teórica fundada em práticas, valores, leis, que visam explicar o mundo de determinada maneira a qual não é absoluta, inquestionável. Ainda sobre a questão reflete Habermas: "Tornou-se costume aplicar à história da filosofia o conceito de "paradigma", oriundo da história da ciência, e dividir as épocas históricas com o auxílio de "ser", "consciência" e "linguagem". (HABERMAS. Pensamento pós-metafísico... p. 21-22).

6 MATOS, Olgária. Discretas esperanças: reflexões filosóficas sobre o mundo contemporâneo. São Paulo: Alexandria, 2006, p. 21. 
natureza e do mundo e ao medo da destruição, relacionando-se ao "delírio" e não ao campo ético...

Ao se posicionar em um patamar acima da humanidade, a ciência moderna, por sua vez, produziu um sujeito abstrato que podia ser quantificável, previsível. Isso se deu na busca científica pela dominação do mundo natural. Não observou, contudo, o fato de que o ser humano não aceita essas medidas, as categorias tratadas de maneira absolutizante das hard sciences. A coisificação dos indivíduos, contemporaneamente, relaciona-se com os valores do mercado total (globalização econômica e sem alternativas) que se desvinculou da ética e desencantou o mundo ${ }^{7}$.

Mitigados os valores ligados à dignidade da pessoa humana ${ }^{8}$, convertem-se os seres humanos em personagens da sociedade de consumo, eis que, o capitalismo tardio busca consumidores e não cidadãos ${ }^{9}$. A economia como racionalidade reinante da sociedade de consumo opõe-se à autonomia da consciência das pessoas, como observado por Olgária Matos “... o indivíduo atomizado da sociedade de massa conhece o preço de todas as coisas, mas desconhece o seu valor. A economia apresenta-se como única maneira de pensa e de ser."10

As utopias modernas ${ }^{11}$ vislumbraram que um mundo estático poderia alcançar a perfeição. Além de perfeito e imóvel ele seria transparente, puro. Tal forma de entendimento acabou por levar à exclusão da existência do outro, na negação da

${ }^{7}$ Sobre o tema, faz-se referência o poeta Manoel de Barros: "A ciência pode classificar e nomear os órgãos de um sabiá, mas não pode medir os seus encantos. A ciência não pode calcular quantos cavalos de força existem nos encantos de um sabiá. Quem acumular muita informação perde o condão de adivinhar: divinare. Os sabiás divinam." (BARROS, Manoel de. Livro sobre nada. Rio de Janeiro: Record, 1997).

${ }^{8} \mathrm{O}$ conceito de dignidade da pessoa humana será desenvolvido ao longo da monografia, contudo, registra-se que a modernidade passou a desrespeitar (ou para alguns nunca respeitou) o seu próprio conceito de dignidade humana, formulado por Kant em sua obra: Fundamentação da metafísica dos costumes. Ver: KANT, Immanuel. Fundamentação da metafísica dos costumes. São Paulo: Abril Cultural, 1980.

${ }^{9}$ A cidadania dialoga com o valor moderno da autonomia, apresentando-se no campo político.

${ }^{10}$ MATOS, op. cit., p. 77.

11 “... el problema de la utopía se encuentra em todos los pensamientos que aparecen en la modernidad, incluso en la llamada postmodernidad, la que, por otra parte, hay que interpretar como una variación (Spielart) de la modernidad y nada más." (HINKELAMMERT, Franz. Crítica de la razón utópica. Bilbao: Desclée de Brouwer, 2002, p. 387). 
CRISE E TRANSMODERNIDADE: FUNDAMENTOS INICIAIS PARA UMA ÉTICA DA LIBERTAÇÃO

alteridade $^{12}$ e das possibilidades de diferentes paradigmas, de outras realidades. A busca da purificação centralizou e coletivizou atividades, as quais, por sua vez, foram substituídas por estratégias desregulamentadoras e privatizadoras, assentes aos conceitos neoliberais $^{13}$. Isso levou ao ressentimento do espírito moderno, de constante progresso contra a tradição e, no mesmo fluxo, o Estado sublimou sua antiga missão de promoção de modelos de ordem, passando a adotar sua forma mínima.

\subsection{AS FACES EXCLUDENTES DO PROJETO MODERNO}

No mundo globalizado, a organização e a ordem transpuseram-se como valores do mercado total, na busca de constante renovação, adaptando-se aos infindáveis anseios advindos de sua incansável ampliação, visando novos consumidores. Em resumo, na culminação do vigente poder da globalização econômica $^{14}$, a qual se coloca como sem possibilidades de alternativas, inexistem, assim, outros mundos possíveis ${ }^{15}$.

A busca pela purificação dos locais de convívio promovida pelo ideário da

${ }^{12}$ Conforme Dussel: “... se adota como própria a alteridade das vítimas, dos dominados, a exterioridade dos excluídos em posição crítica, desconstrutiva da "validade hegemônica" do sistema, agora descoberto como dominador: o capitalismo, o machismo, o racismo, etc." (DUSSEL, Enrique. Ética da libertação. Na idade da globalização e da exclusão. 2. ed. Petrópolis: Vozes, 2002, p. 315).

13 "Desregulação, privatização, mercado interno do Estado, comparticipação nos custos, mercadorização, cidadania activa, ressurgimento da comunidade são algumas das denominações do variado conjunto de políticas estatais com o objectivo comum de reduzir a responsabilidade do Estado na produção de bem-estar social." (SANTOS, Boaventura de Sousa. Crítica da razão indolente: contra o desperdício da experiência. São Paulo: Cortez, 2000, p. 155).

${ }^{14}$ De acordo com Bauman: "Los procesos globalizadores incluyen uma segregación, separación y marginación social progresiva.” (BAUMAN, Zygmnut. La globalización. Consecuencias humanas. Buenos Aires: Fondo de Cultura Econômica, 2006, p. 9).

15 "En efecto, las alternativas que se presentan como sociedades para las que no hay alternativa - el socialismo estaliniano y el capitalismo del mercado total -, no son alternativas potenciales. Su afirmación de que para ellas no existe alternativa, revela que no son alternativas posibles. Cualquier sociedad que sostenga que no hay alternativa para ella, demuestra que nos es ninguna alternativa. De ella podemos decir a priori, que solo se puede legitimar por el suicídio colectivo.” (HINKELAMMERT. Crítica ..., p. 301). 
ordem moderna confrontou com os estranhos, de modo que os padrões de pureza estabelecidos não foram suficientes, face às novas realidades insurgentes, as quais se renovam constantemente, trazendo instabilidade aos ambientes ${ }^{17}$.

Agregados à urgência social por segurança, se tornaram mais robustos os ideais de fim do Estado Social de Direito ${ }^{18}$ e da insuficiência do Estado provedor. A partir da sociedade de risco $^{19}$, tida como pós-moderna, não é mais factível, para o referido discurso, a presença do Estado Social de Direito. Assim, o ideal de proteção daqueles que ficavam à margem da sociedade, como as pessoas sem emprego, não se sustenta mais para os neo-conservadores, de modo que não deve ser responsabilidade do Estado reintegrá-los à sociedade ${ }^{20}$.

Importante evidenciar que, mesmo o neoliberalismo, não se instalou completamente, como observado por Loïc Wacquant ${ }^{21}$ no seguinte paradoxo:

${ }^{16}$ Os padrões de pureza ou discursos de pureza consistem na negação da alteridade, das diferenças, do outro.

$17 \mathrm{O}$ paradoxo temporal e conceitual que se coloca diz respeito à incapacidade da modernidade em lidar com o eterno futuro, com as mudanças infindáveis que o próprio paradigma gestou em sua formação. Percebe-se, assim, que a modernidade deixou de expressar necessariamente o novo, estabelecendo padrões conservadores para continuar vigente. Essa escolha da modernidade levou à criação de padrões de pureza da ordem moderna, os quais metodicamente excluem aquelas pessoas que não se adequam aos seus discursos. Essa realidade se agrava em realidades periféricas, como no caso do Brasil.

${ }^{18}$ Conforme enuncia Paulo Bonavides: "Com o Estado social, o Estado-inimigo cedeu lugar ao Estado-amigo, o Estado-medo ao Estado-confiança, o Estado-hostilidade ao Estado-segurança. As Constituições tendem assim a se transformar num pacto de garantia social, num seguro com que o Estado administra a Sociedade. (BONAVIDES, Paulo. Curso de direito constitucional. 14. ed. São Paulo: Malheiros, 2004, p. 380).

${ }^{19}$ De acordo com Ulrich Beck: "La sociedad de riesgo significa que el pasado pierde su fuerza determinante para el presente, y en su lugar hace su entrada el futuro, es decir, algo no existente, sino construído y fictício como causa de la experiência y el quehacer presentes. Cuando hablamos de riesgos, discutimos de algo que no está a la vista, pero que puede hacer su aparición si no se toman ahora mismo cartas en el asunto. (BECK, Ulrich. ¿Qué es la globalización? Falácias del globalismo, respuestas a la globalización. Barcelona: Paidós, 1998, p. 143).

${ }^{20}$ Desse modo, não haveria nem razões sociais bem como morais para a permanência do Estado de bem-estar social. A referida visão de mundo “... já não considera conveniente ou desejável subscrever os custos sociais e humanos da solvência econômica (que, sob condições de mercado, é equivalente à lucratividade). Em vez disso, transfere o pagamento às próprias vítimas, presentes e futuras." (BAUMAN, Zygmunt. O mal-estar na pós-modernidade. Rio de Janeiro: Zahar, 1998, p. 52).

21 “Comment la 'tolérance zéro' vint à 1'Europe” Apud (BAUMAN. Vidas desperdiçadas. Rio de Janeiro: Zahar, 2005, p. 105). 
As mesmas pessoas que ontem lutavam com visível sucesso por "menos Estado", a fim de libertar o capital e o modo como ele usava a força de trabalho, hoje em dia exigem vigorosamente "mais Estado" para conter e ocultar as deletérias conseqüências sócias da desregulamentação das condições de emprego e da deteriorização da proteção concedida pela sociedade às regiões inferiores do espaço social.

Sob essa perspectiva, os padrões de pureza geram sua própria sujeira, na mesma proporção em que cada ordenamento cria seus excluídos. Faz-se notar, portanto, que o paradigma tido como pós-moderno traz renovadas formas de exclusão. Mesmo dentro da organização do mercado, que se arroga atingir a todos sem distinções, os consumidores inaptos a transpor as novas provas de pureza da modernidade, são a piori, marginalizados ${ }^{22}$. Considerados como os estranhos da era de consumo $^{23}$ são os novos impuros que precisam ser extirpados do convívio social.

A sociedade de risco combate os marginais, os excluídos da sociedade de consumo, de várias formas. No que diz respeito ao Direito, o uso, em especial do Direito Penal, funciona como barreira de controle daqueles que são colocados à margem da sociedade. $\mathrm{O}$ resultado disso são os crescentes índices de criminalidade, a construção de mais unidades carcerárias e o urgente apelo da sociedade para a tomada de medidas políticas que afastem, extirpem esse mal - consumidores falhos - da sociedade.

Os consumidores falhos, os demônios interiores ${ }^{24}$, são isolados em áreas afastadas dos grandes centros urbanos, instalados em novas formas de guetos. A indústria da prisão, por sua vez, se torna outro depósito humano onde são alojados os refugos da sociedade. O fato de ser pobre torna-se, sob o império das relações de consumo, um crime, enquanto que o empobrecimento é uma forte predisposição para a

22 "Esses poucos fatos anunciam o novo papel atribuído aos pobres na nova versão da "classe baixa", ou da "classe além das classes": ela não é mais o "exército de reserva da mão-de-obra" mas, verdadeiramente, a "população redundante.” (BAUMAN. O mal-estar ..., p. 59).

${ }^{23}$ Conceito emprestado de Bauman (ibidem, p. 49).

24 “Quanto mais poderosos se tornavam os "demônios interiores”, mais insaciável se fazia o desejo daquela maioria de ver "o crime punido" e "a justiça distribuída"." (Ibidem, p. 58). 
exclusão dos inimigos ${ }^{25}$.

Face à impossibilidade da manutenção e sustentação do Estado Social de Direito, em conjunto com o presente agravamento das desigualdades nas sociedades, resta evidenciado o aprofundamento da polarização, entre centro do mundo e periferia, Norte e Sul. Ganham visibilidade, ainda que de maneira restrita, as formas de opressão que operam em níveis diversos, formando, assim, uma base para o questionamento da qualidade $^{26}$ e da quantidade ${ }^{27}$ de vida produzida pela transição paradigmática da modernidade.

\section{Por meio da atualização constante das formas de exclusão, a} modernidade produziu hordas de marginalizados. Estes, em sua condição de poluidores $^{28}$ do meio social, legitimam as exigências feita pelos reguladores da pureza ao determinar a lei e a ordem ${ }^{29}$, pela atuação inquisitorial do direito penal e pelo aumento de segurança social e jurídica. Explicita-se, nesse sentido, a falência da compreensão humanista $^{30}$ da cidadania e da democracia no paradigma da modernidade.

${ }^{25}$ A retomada de discursos excludentes, como se faz perceber, exemplificativamente, no Direito Penal do Inimigo. Teoria de Günter Jakobs, em que se especificam as pessoas sobre as quais o Direito Penal deve incidir, penalizar, pelo simples fato de elas serem (diferentes), pelo que elas são e representam; e não pelo que estas fizeram. O penalista alemão anuncia, portanto, que: "Quem por princípio se conduz de modo desviado, não oferece garantia de um comportamento pessoal. Por isso, não pode ser tratado como cidadão, mas deve ser combatido como inimigo. Esta guerra tem lugar com um legítimo direito dos cidadãos, em seu direito à segurança; mas diferentemente da pena, não é o Direito também a respeito daquele que é apenado; ao contrário, o inimigo é excluído." (JAKOBS, Günther; MELIÁ, Manuel Cancio. Direito penal do inimigo: noções e críticas. Porto Alegre: Livraria do Advogado, 2005, p. 49). Discurso que coaduna com a crescente criminalização da pobreza. Essas temáticas foram criticadas de maneira aprofundada por Bauman ver: (BAUMAN. Vidas desperdiçadas..., op. cit.).

${ }^{26}$ Temática que diz respeito ao próprio princípio da dignidade da pessoa humana.

${ }^{27}$ Questão pertinente às temáticas de urgência, como os índices de mortalidade infantil, a fome e a pobreza.

28 "Poluidores" é usado no sentido figurado, são os diferentes, os excluídos.

${ }^{29}$ Movimento de refluxo que exige mais Estado (conforme citação de Loïc Wacquant). A lei simboliza a aplicação da legislação aos destinatários da lei, mormente, não aqueles que a criam; enquanto a ordem pode ser entendida no sentido amplo, nos moldes dos padrões de pureza da modernidade, em colocar cada coisa em seu devido lugar, o que implica na crescente marginalização social.

${ }^{30}$ Utiliza-se a expressão humanista no sentido de afirmação do princípio da dignidade 
Face ao ideário de ordem trazido pela modernidade, é importante pensar sobre a ideologia de pureza consolidada pelos mecanismos delimitadores dessa ${ }^{31}$. Por isso, a pureza moderna não pode ser vista como simples saneadora social, pois continua fundamentando os (ainda presentes) discursos totalitários ${ }^{32}$ (raça pura) e da tentativa frustrada da modernidade em colocar cada coisa em seu devido lugar.

A sujeira é antagônica frente ao paradigma da modernidade, o qual se opõe a tudo aquilo que fica fora da ordem. Desvela-se, dessa forma, a existência de sujeitos excluídos do projeto da modernidade, aqueles aos quais a civilização não reservou espaço dentro de sua ordem. Salta aos olhos que o mundo da pureza não foi capaz de abranger as formas sob as quais não conseguiu fixar seu poder.

Os modelos de pureza se adequam ao momento histórico a que pertencem, variando conforme cada cultura, não podendo ser tratados como absolutos, pois se transmutam a partir da realidade com que lidam. Muito embora sejam entendidos como moldáveis à diversidade histórica humana, frisa-se que as formas de pureza possuem em comum nos seus âmagos o caráter totalizante, excludente, negador da(s) alteridade $(s)^{33}$.

Sob esse prisma, faz-se necessário notar a existência do outro, os diferentes, os

humana.

31 Adorno em suas Anotações sobre Kafka, demonstra que: "Sistemas políticos e de pensamento não desejam nada que não se lhes assemelhe. Porém, quanto mais reduzem tudo o que existe a um denominador comum, tanto mais oprimem e se afastam do que existe. O menor "desvio", por isso, lhes parece ser uma ameaça ao sistema como um todo, algo tão insuportável quanto o estranho e o solitário para os poderosos de Kafka.” (ADORNO, Theodor W. Prismas: crítica cultural e sociedade. São Paulo: Ática, 2001, p. 253).

${ }^{32}$ Um exemplo preocupante de tal questão diz respeito ao crescente xenofobismo europeu, manifestado por partidos de extrema direita como o caso do partido francês Frente Nacional, presidido por Jean-Marie Le Pen.

33 “A pureza da sociedade de consumo, ícone da modernidade, é constantemente repercutida nas propagandas de saponáceos, busca-se a separação, a exclusão, a purificação das roupas. Entendese que a idéia maior de purificação pode ser aplicada no âmbito social, onde se busca a pureza dos locais de convívio. Reflexão realizada por Barthes sobre os saponáceos pode ser lida a partir de uma perspectiva que contemporânea dos atores, em que o Omo é a sociedade de consumo e a sujeira, a alteridade negada, os excluídos; dessa forma: “... os pós são elementos separadores: o seu papel ideal consiste em libertar o objeto da sua imperfeição circunstancial: "expulsa-se" a sujeira, mas esta não morre; na propaganda visual do Omo, a sujeira é representada por um pequeno inimigo débil e negro que foge apavorado da roupa limpa e pura, sob a simples ameaça do julgamento do Omo." 
marginalizados, os quais se tornam expressões da sujeira, da desordem e da impossibilidade de organização do ambiente. A partir desse ideário, a perturbação da realidade, dos tidos como comuns, ou seja, dos pertencentes à ordem, tem início com a chegada do estranho, do diferente, pondo fim à segurança previamente reinante.

Questionar, contestar, ser em si estranho ao meio, são os crimes que colocarão o estranho fora do padrão social. O outro assume o papel de desafiar a ordem estabelecida, bem como todo o processo civilizatório. Aqueles que não foram abraçados pela modernidade tornar-se-ão, gradativamente, alvo da separação, da exclusão (como historicamente se observa), formando o que pode ser chamado, contemporaneamente, de as novas invasões bárbaras; todos aqueles excluídos da modernidade, os sem-direitos, os quais denunciam, em suas existências, a disparidade das formas de vida, as violações dos direitos humanos.

A promessa de rompimento com os valores da tradição trazida no projeto paradigmático da modernidade não foi cumprida ${ }^{34}$ mas, estabeleceu um estado de começo permanente. Dessa maneira, novos alvos de sujeira ${ }^{35}$ passaram a emergir, criando um sistema contínuo de exclusão, a partir do qual, se torna possível afirmar o

(BARTHES, Roland. Mitologias. 9. ed. São Paulo: Bertrand Brasil, 1993, p. 29).

${ }^{34}$ Sobre o espírito revolucionário, contestador da modernidade, David Harvey expõe que: “... não é difícil ver que alguma espécie de transformação radical de fato ocorreu nesses anos. $O$ caminho de Swan, de Proust (1913), os Dublinenses, de Joyce (1914), Filhos e Amantes, de Lawrence (1913), Morte em Veneza, de Mann (1914), e o "Manifesto Vorticista", de Pound, escrito em 1914 (em que ele comparava a linguagem pura com a eficiente tecnologia da máquina), são alguns dos textos-marco publicados numa época que também testemunhou uma extraordinária e florescência na arte (Matisse, Picasso, Brancusi, Duchamp, Braque, Klee, de Chirico, Kandinsky, que exibiram muitas obras no famoso Armory Show de Nova Iorque em 1913, obras que foram vistas por mais de 10.000 visitantes por dia), na música ( $O$ despertar da primavera, de Stravinsky, provocou uma revolução em 1913 e teve como paralelo a chegada da música atonal de Schoenberg, Berg, Bartok e outros), para não falar da dramática mudança na lingüística (a teoria estruturalista da linguagem de Saussure, em que o sentido das palavras é determinado antes pela sua relação com outras palavras do que pela sua referência a objetos, foi concebida em 1911) e na física, a partir da generalização da teoria da relatividade de Einstein, com seu recurso às, e sua justificação material das geometrias nãoeuclidianas. Igualmente significativa foi a publicação, em 1911, de Os princípios da administração científica, de F. W. Taylor, dois anos antes de Henry Ford instalar a primeira linha de produção em Dearborne, Michigan.” (HARVEY, David. Condição pós-moderna. 13. ed. São Paulo: Loyola, 2004, p. 36).

35 "Podemos dar um passo adiante e dizer que a 'colocação em ordem', agora, se torna indistinguível da proclamação de sempre novas 'anormalidades', traçando sempre novas linhas divisórias, identificando e separando sempre novos 'estranhos'.” (BAUMAN. O mal-estar ..., p. 20). 
CRISE E TRANSMODERNIDADE: FUNDAMENTOS INICIAIS PARA UMA ÉTICA DA LIBERTAÇÃO

caráter anti-moderno da própria modernidade, no que tange, principalmente, aos valores que a estabeleceram. Conservadora, a modernidade das revoluções, das transformações que ocorrem no início de século XX, teve seus valores filtrados e absorvidos pelo establishment e passou, sistematicamente, a atender à tradição.

\section{FUNDAMENTOS DA CRÍTICA À MODERNIDADE: UM PROJETO NÃO CUMPRIDO}

A Teoria Crítica da Escola de Frankfurt, já evidenciou que a simples vontade de concretização dos valores da modernidade não corresponde, necessariamente, em sua faticidade, conforme expressado por Horkheimer ${ }^{36}$ em sua célebre obra Teoria tradicional e teoria crítica:

O desejo de um mundo sem exploração nem opressão, no qual existiria um sujeito agindo de fato, isto é, uma humanidade autoconsciente, e no qual surgiriam as condições de uma elaboração teórica unitária bem como de um pensamento que transcende os indivíduos, não representa por si só a efetivação desse mundo.

A civilização contemporânea pode ser entendida, dentre outras formas, como uma tentativa frustrada de reprodução do discurso da modernidade. Simbolicamente questionada em sua incapacidade de representar o novo, a modernidade, além de não cumprir suas promessas, não implementou sua tríade fundamental ${ }^{37}$, o que acarretou em pensamentos acerca das diversas saídas do paradigma moderno, na presente transição paradigmática.

A crise da modernidade ${ }^{38}$ consiste nas várias mudanças que se articulam na

${ }^{36}$ HORKHEIMER, Max. Teoria tradicional e teoria crítica. São Paulo: Abril Cultural, 1975, p. 161.

${ }^{37}$ Universalidade, individualidade e autonomia.

38 A crise consiste, em sua singela concepção, na mudança de algum processo; a modernidade, como já foi exposto, implica na ruptura com a tradição e na instauração do novo. Cria- 
civilização moderna e em suas formas de compreensão. Com o advento do conceito de crise, abdicou-se da estabilidade e da fixação de conceitos rígidos para se diagnosticar as transições paradigmáticas, abrindo-se as portas para uma pluralidade de novos discursos.

Inobstante isto, entende-se que foram promovidos esvaziamentos dos conteúdos e dos valores da modernidade, mudando seus significados. A individualidade se tornou o individualismo cego para as questões sociais e a coroação da sociedade de consumo, além de não constituir uma garantia contra genocídios ou contra a contabilização fria (como estatística) dos mortos.

A universalidade não passou do âmbito da retórica, verificando-se o crescimento de excluídos na sociedade pelo fato de que a igualdade formal ainda é uma busca distante da realidade. Também sob o véu da universalidade se fundamentam discursos totalitários, unidimensionais, existindo grande crítica acerca do conteúdo da universalidade, questionando se esta não constituiria, na verdade, em uma nova forma de colonização ou de imposição unilateral de valores ocidentais.

A autonomia aprofundou o ideário do individualismo, ao passo que a vertente emancipatória desse valor foi sublimada por reiteradas formas de alienação ${ }^{39}$. Ainda sobre a autonomia, percebe-se a dificuldade da implementação fática desta nos âmbitos: intelectual, político e econômico.

O processo civilizatório, aliado ao discurso (inicial) da modernidade ${ }^{40}$, acarretou em uma transição paradigmática ${ }^{41}$ dentro da própria ordem moderna, a qual

se, em um primeiro momento, um vício de linguagem ou uma tautologia. Essa situação pode ser resolvida se pensarmos a modernidade, como anti-moderna, como conservadora, e desprendida de sua semântica inicial. A crise, portanto, seria o fator de transformação do paradigma enquanto a modernidade, paradoxalmente, seria o fator conservador a ser transformado.

Terra, 2002.

${ }^{39}$ Sobre a questão: ADORNO, Theodor W. Indústria cultural e sociedade. São Paulo: Paz e

${ }^{40}$ Constante renovação, mudança de tempos etc.

41 Sobre transições paradigmáticas expõe Kuhn: "Comecemos examinando um caso particularmente famoso de mudança de paradigma: o surgimento da astronomia copernicana. Quando de sua elaboração, durante o período de 200 a.C. a 200 d.C., o sistema precedente, o ptolomaico, foi admiravelmente bem sucedido na predição da mudança de posição das estrelas e dos planetas. Nenhum outro sistema antigo saíra-se tão bem: a astronomia ptolomaica é ainda hoje amplamente 
pode ser compreendida, contemporaneamente, de maneiras múltiplas. Nesse âmbito, de acordo com os vários pensamentos existentes acerca da crise paradigmática se torna possível elencá-los como: moderno ${ }^{42}$ (a modernidade não cumpriu suas promessas); pós-moderno $^{43}$ (realização final da modernidade) ou ainda, transmoderno ${ }^{44}$ (em que se aproveitam as críticas da pós-modernidade e o potencial emancipatório da modernidade para se pensar um outro paradigma).

Resta explícito que, qualquer uma das formas adotadas tem a crise $^{45}$ como aspecto fundamental e, esta passou a desestruturar o paradigma da modernidade ${ }^{46}$. Deve-se estabelecer ainda o fato de que as conseqüências da transição paradigmática,

usada para cálculos aproximados; no que concerne aos planetas, as predições de Ptolomeu eram tão boas como as de Copérnico. Porém, quando se trata de uma teoria científica, ser admiravelmente bem sucedida não é a mesma coisa que ser totalmente bem sucedida." (KUHN, op. cit., p. 95-96). Percebese, assim, que o novo paradigma não necessariamente rompe ou elimina o anterior, mas que, por outro lado, Kuhn estabelece um parâmetro eminentemente pragmático de validade dos paradigmas.

${ }^{42}$ Em diferentes sentidos, Jürgen Habermas, Zygmunt Bauman e Sergio Paulo Rouanet acreditam que o paradigma vigente ainda é o moderno. Ver, respectivamente: (HABERMAS, op. cit.; BAUMAN, Zygmunt. "A sociedade líquida." Folha de São Paulo, São Paulo,19 out. 2003; ROUANET, op. cit.).

${ }^{43}$ Sob diferentes perspectivas, Jean-François Lyotard, Boaventura de Sousa Santos e David Harvey, entendem que o paradigma moderno foi superado, ou que a transição paradigmática nos leva por esse caminho. Ver, respectivamente: (LYOTARD, Jean-François. A condição pós-moderna. 5. ed. Rio de Janeiro: José Olympio, 1998; SANTOS, op. cit.; HARVEY, op. cit.).

${ }^{44}$ Conceito de Enrique Dussel muito bem explicado por Ana Letícia Medeiros: "Proposta por Enrique Dussel, a transmodernidade, metodologicamente também é conhecida como paradigma "da vida concreta de cada sujeito", apresenta-se como uma alternativa à crise paradigmática acima narrada, como uma quarta referência teórica, para além da pré-modernidade, da modernidade e da pósmodernidade. Contudo, enfatiza-se que não há aqui uma ruptura epistemológica radical, mas sim uma subsunção dialética dos paradigmas anteriores." (MEDEIROS. Direito internacional dos direitos humanos..., p. 43. Ver também: DUSSEL, op. cit.).

45 "Neste período de transição de milênio, o paradigma epistêmico estatocêntrico das ciências sociais e jurídicas vem, gradativamente, atravessando um período de crise, em especial diante dos fenômenos que compõem a mundialização e da emergência da chamada sociedade global. Em tempos ditos pós-modernos, um complexo de processos de fragmentação impera no cenário internacional, envolvendo as mais diversas áreas da vida como um todo e provocando mudanças altamente significativas, em especial nos países com padrão de vida mais baixos." (MEDEIROS, ibidem, p. 1).

${ }^{46}$ Acerca da crise da modernidade reflete Rouanet: "Todos dizem que a modernidade está em crise. É um lugar-comum, mas como outros lugares-comuns este pode ser até verdadeiro, desde que se entenda bem o alcance do diagnóstico. O que existe atrás da crise da modernidade é uma crise da civilização. O que está em crise é o projeto moderno de civilização, elaborado pela Ilustração européia a partir de motivos da cultura judeo-clássica-cristã e aprofundado nos dois séculos subseqüentes por movimentos como o liberal-capitalismo e o socialismo." (ROUANET, op. cit., p. 9). 
em um contexto periférico, no hemisfério sul do mundo, são diversas da conjuntura eurocêntrica $^{47}$.

Nos períodos de transição paradigmática, a questão que se coloca sobre a natureza dessa fase não tem uma resposta estabelecida. Os critérios basilares da construção conceitual paradigmática estão na pauta dos questionamentos. Desse modo, indaga-se sobre o estado da estrutura valorativa e conceitual da ordem vigente, para saber se existe ou não uma outra forma de percepção da realidade ou, se as bases do paradigma questionado são as mesmas ${ }^{48}$.

\subsection{CONTEMPORANEIDADE: MODERNA OU PÓS-MODERNA?}

A importante distinção conceitual realizada por Boaventura de Sousa Santos ${ }^{49}$ diz respeito aos posicionamentos estabelecidos perante a pós-modernidade: o primeiro, conservador, que entende esta atue como reconfortante, celebratória, e o segundo, adotado pelo sociólogo, manifesta-se a favor de uma visão inquietante, de resistência.

Desta forma, o primeiro conceito delineado como mais conservador, entende que ante o fato de inexistirem soluções modernas para os problemas do paradigma que

47 "Enquanto os países centrais tenderam a ser externa e internamente fortes, externamente rígidos e internamente flexíveis, os países periféricos tenderam a ser débeis externa e internamente, externamente flexíveis e internamente rígidos.” (SANTOS, op. cit., p. 171). A temática será desenvolvida no tópico referente à transmodernidade.

48 "No hay aún una cultura de la post-modemidad establecida. Lo que hay es una búsqueda a partir de la constatación de una ruptura necesaria. Vivimos en plena cultura de la modernidad, pero ya no podemos creer em ella. Eso ya lo revela la propia palabra post-modernidad. Ninguna época nueva se llama post-época anterior. La sociedad burguesa no se llama post-feudal, ni la sociedad socialista post-burguesa." (HINKELAMMERT. Franz. Frente a la cultura de la post-modernidad: proyecto político y utopía. Revista Pasos, San José de Costa Rica, n.12, p. 1-11, jul. 1987).

49 "Segundo uma posição, que podemos designar por pós-modernidade reconfortante, o facto de não haver soluções modernas é indicativo de que provavelmente não há problemas modernos, como também não houve antes deles promessas da modernidade. Há, pois, que aceitar e celebrar o que existe. Segundo outra posição, que designo por pós-modernidade inquietante ou de oposição, a disjunção entre a modernidade dos problemas e a pós-modernidade das possíveis soluções deve ser assumida plenamente e deve ser transformada num ponto de partida para enfrentar os desafios da construção de uma teoria pós-moderna." (SANTOS, op. cit., p. 29). 
CRISE E TRANSMODERNIDADE: FUNDAMENTOS INICIAIS PARA UMA ÉTICA DA LIBERTAÇÃO

se apresentam (no que tange à crise do paradigma), não haveria problemas modernos. Sendo assim, do mesmo modo que a modernidade não fez promessas, dever-se-ia seguir a única saída de celebrar o existente.

Já o segundo conceito, parte da premissa que a modernidade deve assumir sua crise e, assim, a pós-modernidade poderia apresentar soluções, implicando na construção de um marco inicial para a edificação de uma teoria crítica pós-moderna.

O paradigma tido como pós-moderno ${ }^{50}$ tem por natureza a indefinição, em que se constitui qualquer transição do paradigma vigente. A modernidade não é a mesma, não atende nem aos anseios transformadores dos idos de 1900 nem à sua forma sólida ${ }^{51}$, estabelecida principalmente por meio do positivismo, da tecnocracia e do racionalismo como valores universais ${ }^{52}$.

A crise da modernidade é observada como um momento de tensão epistemológica e social, compreendendo-se quatro grandes formas interpretativas da

50 "É nesse sentido que pós-modernidade é, para mim, modernidade sem ilusões. Diferentemente da sociedade moderna anterior, a que eu chamo de modernidade sólida, que também estava sempre a desmontar a realidade herdada, a de agora não o faz com uma perspectiva de longa duração, com a intenção de torná-la melhor e novamente sólida. Tudo está agora sempre a ser permanentemente desmontado, mas sem perspectiva de nenhuma permanência." (BAUMAN. "A sociedade ..., op. cit.).

51 "O tipo de modernidade que era o alvo, mas também o quadro cognitivo, da teoria crítica clássica, numa análise retrospectiva, parece muito diferente daquele que enquadra a vida das gerações de hoje. Ela parece "pesada" (contra a "leve" modernidade contemporânea); melhor ainda, "sólida" (e não "fluida", "líquida" ou "liquefeita"); condensada (contra difusa ou "capilar"); e, finalmente, "sistêmica" (por oposição a "em forma de rede")." (Ibidem, p. 33).

52 "Geralmente percebido como positivista, tecnocêntrico e racionalista, o modernismo universal tem sido identificado com a crença no progresso linear, nas verdades absolutas, no planejamento racional de ordens sociais ideais, e com a padronização do conhecimento e da produção. O pós-moderno, em contraste, privilegia "a heterogeneidade e a diferença como forças libertadoras na redefinição do discurso cultural". A fragmentação, a indeterminação e a intensa desconfiança de todos os discursos universais ou (para usar um termo favorito) "totalizantes" são os marcos do pensamento pós-moderno. A redescoberta do pragmatismo na filosofia (p. ex., Rorty, 1979), a mudança de idéias sobre a filosofia da ciência promovida por Kuhn (1962) e Feyerabend (1975), a ênfase foucaultiana na descontinuidade e na diferença na história e na primazia dada por ele a "correlações polimorfas em vez da casualidade simples ou complexa", novos desenvolvimentos na matemática - acentuando a indeterminação (a teoria da catástrofe e do caos, a geometria dos fractais) - o ressurgimento da preocupação, na ética, na política e na antropologia com a validade e a dignidade do "outro" - tudo isso indica uma ampla e profunda mudança na "estrutura do sentimento". O que há em comum nesses exemplos é a rejeição das "metanarrativas" (interpretações teóricas de larga escala pretensamente de aplicação universal)...” (HARVEY, op. cit., p. 19). 
transição paradigmática ${ }^{53}$ : a primeira entende que o capitalismo triunfou e isso se expressa como a maior realização da modernidade, tendo como expoente Fukuyama e sua tese do fim da história; a segunda defende que a modernidade como projeto inacabado com prerrogativas cognitivas e políticas para a concepção de um mundo sem o capitalismo, defendida por Habermas; a terceira forma interpretativa deduz que a modernidade pereceu ante o capitalismo, o qual, por sua vez, assumirá uma formatação pós-moderna em suas manifestações sócio-culturais, posição defendida por Lyotard, também conhecida como pós-modernidade conservadora ou celebratória; por fim, a quarta interpretação percebe o fim da modernidade com projeto epistêmico e cultural, e propõe, a seu modo, um futuro não-capitalista, a partir da uma pósmodernidade de resistência, de oposição, inquietante ${ }^{54}$.

Denota-se, ainda, que o paradigma crítico adotado como horizonte para Boaventura de Sousa Santos tem por opção a fundamentação a partir da alteridade, “... ou seja, pelo reconhecimento de múltiplas existências humanas, num mesmo mundo, de forma concomitante, porém de conteúdo exacerbadamente diferente ${ }^{55}$,

\section{A PROPOSTA DA TRANSMODERNIDADE: EM BUSCA DA ALTERIDADE}

Para além do relevante debate existente sobre os plurais diagnósticos acerca da modernidade: se o paradigma ainda se encontra vigente (e deveria ser implementado) ou se não existem mais soluções, instrumentos, modernos capazes de fixar o projeto da modernidade; a transmodernidade, se apresenta como uma

53 As quatro grandes formas interpretativas citadas seguem esquema desenvolvido em: SANTOS, op. cit., p. 166-167).

54 "De outra feita, os pós-modernos de oposição acreditam na possibilidade da reinvenção das promessas modernas ainda não cumpridas. Porém, diante de um mundo multicultural, com a predominância hegemônica do economicamente mais forte sobre o hipossuficiente, tal proposta implica em repensar alternativas críticas ao mundo flagrantemente desigual." (MEDEIROS, op. cit., p. $40)$.

${ }^{55}$ Ibidem, p. 39. 
possibilidade, não-hegemônica, de construção de um outro paradigma a partir dos conceitos que entende como positivos ${ }^{56}$, da modernidade e da pós-modernidade, deixando de lado seus aspectos totalizantes ${ }^{57}$.

A proposta do paradigma da transmodernidade, também conhecido como paradigma da vida concreta de cada sujeito, tem como método a subsunção dialética dos paradigmas até então vigentes. Nesse sentido, Ana Letícia B. D. Medeiros ${ }^{58}$ expõe:

Desse modo, para a transmodernidade subsumir (termo negritado em razão de sua importância basilar para a compreensão desta proposta de fundamentação) significa, de forma simplificada, aproveitar da modernidade o seu caráter emancipatório, negando, por outro lado, seu caráter transcendental e eurocêntrico; e da pós-modernidade, usar a sua crítica, abstraindo, de outra parte, seu caráter niilista. É agora o momento de pensar o "mundo" a partir de uma realidade exterior, reconhecendo desde o início o centrismo da visão européia, compreendendo que o "não-ser" também é, através de um evidente constatação das diferenças existentes.

De acordo com o entendimento da Ética da Libertação ${ }^{59}$, suscita-se a necessidade da libertação teórica e da práxis, a ruptura com a dominação e dependência fática, bem como com as ideologias de dominação. Conforme exposto por Celso Ludwig60: “A Libertação da Filosofia compreende a produção de um contradiscurso, uma Filosofia crítica que surge na periferia do mundo a partir das vítimas e dos excluídos, hoje com pretensão de mundialidade”.

A partir da necessidade de libertação do eurocentrismo filosófico, objetivando a criação de um pensamento periférico, uma epistemologia dos excluídos, afirma-se a razão produzida pela alteridade negada. Requer-se, portanto, o reconhecimento e a legitimação dos discursos que partem de pontos negados pela tradição hegemônica, in

${ }^{56} \mathrm{O}$ caráter emancipatório da modernidade e a crítica da pós-modernidade.

${ }^{57} \mathrm{Da}$ modernidade, sua natureza transcendental e eurocêntrica. Da pós-modernidade, seu niilismo.

${ }^{58}$ MEDEIROS, ibidem, p. 44.

${ }^{59}$ DUSSEL, op. cit.

${ }^{60}$ LUDWIG, Celso Luiz. "Filosofia da libertação". In: BARRETO, Vicente de Paulo (org.). Dicionário de filosofia do direito. Rio de Janeiro/Porto Alegre: Renovar/Unisinos, 2006. p. 327. 
casu, os discursos provenientes da América Latina.

A partir do sujeito como realidade, reflete-se acerca de uma racionalidade pautada pela alteridade, a exterioridade do outro real não mais fundada na idealização de um consenso meramente formal, em condições ideais de comunicação que rejeitam as éticas materiais, mas, desde o dissenso ${ }^{61}$ a filosofia transmoderna passará a assegurar um lugar, uma voz para os que tiveram sua alteridade negada, aqueles não constantes na teoria do discurso e com novo sentido passará a fundamentar novos direitos e novas verdades ${ }^{62}$. A premissa é que antes do discurso, deve haver vida (bios), no sentido de que as pessoas, no mínimo, necessitam ter asseguradas as condições de produção, reprodução e desenvolvimento da vida humana ${ }^{63}$.

Proposto pela Filosofia da Libertação o método analético ${ }^{64}$, defendido por Enrique Dussel, entende a afirmação da alteridade real como movimento positivo e

61 "Quando a vítima emite um "juízo de fato crítico" (em última instância, um enunciado descritivo sobre a vida ou a morte da vítima) diante do sistema, irrompe inevitavelmente como dissenso um discurso, uma enunciação, uma interpelação como "ato de fala" que se opõe è consensualidade da validade intersubjetiva da comunidade dominante. Em geral, esse dissenso não é ouvido; é negado, excluído. Somente quando o dissenso se apóia na organização de uma comunidade de dissidentes (as vítimas), que lutam pelo re-conhecimento, que atacam a verdade e a validade do sistema em vista de sua impossibilidade de viver, por terem sido assimetricamente excluídas da discussão daquilo que lhes toca, a partir de um poder objetivo que é impossível evitar, deste dissenso crítico se torna público, e alcança simetria como fruto de uma luta pela verdade. O dissenso tem então um lugar ético de enunciação, e consiste na exterioridade, agora não só re-conhecida, mas também respeitada como real, que é gerada pelas novas comunidades de comunicação consensuais (não a dominante, mas outra, produto da transformação que esse dissenso produziu criativamente)." (DUSSEL, op. cit., p. 470-471).

62 "Valendo-se dos princípios orientadores da transmodernidade, constata-se que, para os direitos humanos, a questão central - porém não única- de sua fundamentação, reside em seu conteúdo, isto é, no momento material, que tem como critério de verdade, a vida humana como modo de realidade (produção, reprodução e desenvolvimento da vida concreta de cada sujeito), e, partindo desse critério, é possível definir seu princípio orientador, com pretensão de universalidade." (MEDEIROS, Ana Letícia B. D. Direito internacional dos direitos humanos e filosofia na América latina: contribuições para uma possível fundamentação crítica. Cadernos do PROLAM/USP, São Paulo, a. 4, v. 2, p. 114, jul./dez. 2005).

63 "Por sobrevivência humana ou por "produção, reprodução e desenvolvimento da vida humana de cada sujeito ético" (...) entenderemos sempre, neste texto, o critério material universal da ética por excelência: a vida humana concreta de cada ser humano.” (DUSSEL, op. cit., p. 636).

64 “"[...] o método analético consiste na afirmação de um âmbito que constitui a exterioridade metafísica do outro - alteridade irredutível à lógica da totalidade e ponto de apoio para a construção de uma lógica da diferença, ao evitar a redução de tudo ao mesmo." (LUDWIG. Filosofia ... p. 329). 
CRISE E TRANSMODERNIDADE: FUNDAMENTOS INICIAIS PARA UMA ÉTICA DA LIBERTAÇÃO

transontológico $^{65}$. A analética aponta para a subjetividade das vítimas ${ }^{66}$, de modo que essas possam descobrir sua condição de oprimidas e assim adquirir consciência e autonomia. A anterioridade do método analético conduz à condição de práxis da alteridade, criticando conteúdo, formas e factibilidade sistêmicas. Nessa perspectiva, o método da Filosofia da Libertação propõe uma dialética positiva, que tem como fonte a alteridade exteriorizada, o outro real.

O projeto da transmodernidade lida, ainda, com as utopias factíveis, as quais passam a ter sua fonte nas comunidades de vítimas, além de realizar a subsunção dos aspectos instrumentais dos paradigmas vigentes, assim, conforme Dussel ${ }^{67}$ :

[...] a partir da intersubjetividade crítica das vítimas, é realizada pela razão críticoinstrumental e pela razão estratégica subsumidas dentro do horizonte ético-material e formalmoral crítico. Trata-se do âmbito da "factibilidade antecipatória", como construção formulada, explícita, da utopia possível como programa de ação. Aqui nos encontramos no aspecto positivo do princípio. A comunidade, a intersubjetividade crítica das vítimas começa a imaginar a utopia. É uma imaginação transcendental ao sistema: se o "atual" não permite que se viva, é preciso imaginar um "mundo onde seja possível viver". A "esperança" como motivação (instinto de vida, do prazer, o dionisíaco de Nietzsche, corrigido como "desejo metafísico" de Lévinas etc.) diante do futuro possível.

A transmodernidade possui, assim, como marco geográfico-teórico a América Latina, onde se formulam propostas para um outro mundo possível, visando a construção de um entendimento que perceba urgência por um mundo em que caibam $\operatorname{todos}^{68}$, segundo um entendimento específico, de uma sociedade justa e igualitária, em

65 "O juízo ético da razão prática crítica negativa é trans-sistêmico, e se o sistema da "compreensão do ser" (no sentido heideggeriano) é o ontológico, seria então pré- ou trans-ontológico: um juízo que procede da realidade de um dado sistema de eticidade. Neste sentido falamos que além (jenseits) do "ser" (se o "ser" é o fundamento do sistema) se dá ainda a possibilidade da afirmação da realidade das vítimas. Trata-se da Alteridade do Outro "como outro" que o sistema. É alteridade da vítima como oprimida (por ex. como classe) ou como excluída (por ex. como pobre), já que a exterioridade da "exclusão" não é idêntica à "opressão"." (DUSSEL, op. cit., p. 304).

66 “"...] as vítimas são re-conhecidas como sujeitos éticos, como seres humanos que não podem reproduzir ou desenvolver sua vida, que foram excluídos da participação na discussão, que são afetados por alguma situação de morte (no nível que for, e há muitos e de diversa profundidade ou dramatismo)." (Ibidem, p. 303).

\footnotetext{
${ }^{67}$ Ibidem, p. 476.

68 "O socialismo se entendia como sistema de propriedade pública, da mesma forma como o
} 
que o indivíduo possa viver dignamente, possa libertar-se.

\section{CONSIDERAÇÕES FINAIS}

A postura de imaginar um outro mundo serve como caminho ético a ser seguido, ante o imperativo da continuidade da existência humana e a urgente sustentabilidade global. Logo, preestabelece-se, na transmodernidade, qualquer modelo que busque a homogeneização universal da sociedade, não devendo haver imposição vertical de modelos sociais, sistemas e instituições, pois esses colidiriam frontalmente com a idéia imanente de pluralidade que subjaz a proposta ética de um mundo onde caibam todos.

A realidade das instituições, em especial na América Latina, leva a constatação da impossibilidade ${ }^{69}$ de aplicação imediata do referido pressuposto ético (mundo onde caibam todos). Essa realidade, por sua vez, não desabilita o projeto que se opõe ao sistêmico suicídio coletivo programado pelas atuais relações de poder.

Faz-se necessário, assim, acreditar na emergência de um outro paradigma, o da transmodernidade, junto do qual é imprescindível pensar que outro mundo é possível, ou melhor, necessário, além da urgência do levante paradigmático da América Latina, a qual não pode mais ter a alteridade de seus sujeitos negada, violada, devendo se libertar a partir de um contradiscurso dos oprimidos, das vítimas, que preze pelos direitos humanos e pela constante busca da dignidade humana.

capitalismo se entende como sistema de propriedade privada. Por isso, não deixam liberdade diante da constituição das instituições. Elas são deduzidas de princípios abstratos, dando lugar a um humanismo abstrato que, em última análise, destrói a própria humanidade." (HINKELAMMERT, Franz. "Pensar em alternativas: capitalismo, socialismo e a possibilidade de outro mundo." In: PIXLEY, Jorge (org.). Por um mundo diferente: alternativas para o mercado global. Petrópolis: Vozes, 2003. p. 20-21).

69 "Na atualidade, são impossíveis de fato; não obstante, o que hoje de fato é impossível nem por isso é utópico. Na Antigüidade, por exemplo, era impossível para o ser humano voar, mas nem por 
CRISE E TRANSMODERNIDADE: FUNDAMENTOS INICIAIS PARA UMA ÉTICA DA LIBERTAÇÃO

\section{REFERÊNCIAS}

ADORNO, Theodor W. Indústria cultural e sociedade. São Paulo: Paz e Terra, 2002.

. Prismas: crítica cultural e sociedade. São Paulo: Ática, 2001.

BAUMAN, Zygmnut. La globalización. Consecuencias humanas. Buenos Aires: Fondo de Cultura Econômica, 2006.

. O mal-estar na pós-modernidade. Rio de Janeiro: Zahar, 1998.

. Vidas desperdiçadas. Rio de Janeiro: Zahar, 2005.

. “A sociedade líquida.” Folha de São Paulo, São Paulo,19 out. 2003.

BARRETO, Vicente de Paulo (org.). Dicionário de filosofia do direito. Rio de Janeiro/ Porto Alegre: Renovar/Unisinos, 2006.

BARROS, Manoel de. Livro sobre nada. Rio de Janeiro: Record, 1997.

BARTHES, Roland. Mitologias. 9. ed. São Paulo: Bertrand Brasil, 1993.

BECK, Ulrich. ¿Qué es la globalización? Falácias del globalismo, respuestas a la globalización. Barcelona: Paidós, 1998.

BONAVIDES, Paulo. Curso de direito constitucional. 14. ed. São Paulo: Malheiros, 2004.

DUSSEL, Enrique. Ética da libertação. Na idade da globalização e da exclusão. 2. ed. Petrópolis: Vozes, 2002.

HABERMAS, Jürgen. $O$ discurso filosófico da modernidade: doze lições. São Paulo: Martins Fontes, 2000.

Pensamento pós-metafísico: estudos filosóficos. Rio de Janeiro: Tempo Brasileiro, 1990.

HARVEY, David. Condição pós-moderna. 13. ed. São Paulo: Loyola, 2004.

HINKELAMMERT, Franz. Crítica de la razón utópica. Bilbao: Desclée de Brouwer, 2002.

. "Pensar em alternativas: capitalismo, socialismo e a possibilidade de outro mundo." In: PIXLEY, Jorge (org.). Por um mundo diferente: alternativas para o mercado global. Petrópolis: Vozes, 2003.

isso era utópico." (Ibidem, p. 21). 
. Frente a la cultura de la post-modernidad: proyecto político y utopía. Revista Pasos, San José de Costa Rica, n.12, p. 1-11, jul. 1987.

HORKHEIMER, Max. Teoria tradicional e teoria crítica. São Paulo: Abril Cultural, 1975. (Col. Os Pensadores).

JAKOBS, Günther; MELIÁ, Manuel Cancio. Direito penal do inimigo: noções e críticas. Porto Alegre: Livraria do Advogado, 2005.

KANT, Immanuel. Fundamentação da metafísica dos costumes. São Paulo: Abril Cultural, 1980. (Col. Os Pensadores).

KOSELLECK, Reinhart. Futuro pasado. Para uma semântica de los tiempos históricos. Barcelona: Paidós,1993.

KUHN, Thomas S. A estrutura das revoluções científicas. 5. ed. São Paulo: Perspectiva, 1998.

LUDWIG, Celso Luiz. Para uma filosofia jurídica da libertação: Paradigmas da filosofia da libertação e direito alternativo. Florianópolis: Conceito, 2006.

. "Filosofia da libertação". In: BARRETO, Vicente de Paulo (org.). Dicionário de filosofia do direito. Rio de Janeiro/Porto Alegre: Renovar/Unisinos, 2006. p. 327.

LYOTARD, Jean-François. A condição pós-moderna. 5. ed. Rio de Janeiro: José Olympio, 1998.

MATOS, Olgária. Discretas esperanças: reflexões filosóficas sobre o mundo contemporâneo. São Paulo: Alexandria, 2006.

MEDEIROS, Ana Letícia B. D. Direito internacional dos direitos humanos na América latina: uma reflexão filosófica da negação da alteridade. Rio de Janeiro: Lumen Juris, 2007.

Direito internacional dos direitos humanos e filosofia na América latina: contribuições para uma possível fundamentação crítica. Cadernos do PROLAM/USP, São Paulo, a. 4, v. 2, jul./dez. 2005.

ROUANET, Sergio Paulo. Mal-estar na modernidade: ensaios. São Paulo: Companhia das Letras, 1993.

SANTOS, Boaventura de Sousa. Crítica da razão indolente: contra o desperdício da experiência.

São

Paulo:

Cortez,

2000. 